\title{
Variations of origin of coronary artery and their importance
}

\author{
D'SOUZA, M. R. ${ }^{1}$, RAY, B. ${ }^{2 *}$, SAXENA, A. ${ }^{3}$, RASTOGI, P. ${ }^{4}$, \\ D'SOUZA, A. S. ${ }^{5}$, GUPTA, C. ${ }^{5}$, MURALIMANJU, B. V. ${ }^{6}$, SHETTY, P. ${ }^{7}$, \\ KUMAR, $\mathrm{V}^{8}$ and KUMAR, $\mathrm{N}^{1}$
}

\author{
${ }^{1}$ Department of Anatomy, Melaka Manipal Medical College, Manipal, Índia \\ ${ }^{2}$ Department of Anatomy, All India Institute of Medical Sciences Bhopal, Bhopal, Madhya Pradesh, 462020, Índia \\ ${ }^{3}$ Department of Anatomy, VCSG Government Medical Science and Research Institute, Srinagar, \\ Uttarakhand, Índia \\ ${ }^{4}$ Department of Forensic Medicine, Kasturba Medical College, Mangalore, 576104, Índia \\ ${ }^{5}$ Department of Anatomy, Kasturba Medical College, 576104, Manipal, Índia \\ ${ }^{6}$ Kasturba Medical College, Manipal University, 575004, Mangalore, Marrocos \\ ${ }^{7}$ Department of Anatomy, Manipal College of Medical Sciences, Pokhara, Nepal \\ ${ }^{8}$ Department of Anatomy, Sapthagiri Institute of Medical Sciences \& Research Institute, Bangalore, Índia \\ *E-mail: biswabina.ray@gmail.com
}

\begin{abstract}
Introduction: Incidence of anomalous coronary arteries is rare and has been recognized as the causative factor for myocardial ischemia and sudden death. Knowledge about the variations of coronary arterial origin and its course provide a valuable guide to Cardiothoracic Surgeons and Physicians and be useful for producing devices appropriate for variant anatomical structures. The aim of the study was to investigate the number and position of the coronary ostia, emphasizing their possible clinical implications. Methods: Fifty one formalin fixed adult heart specimens were dissected to conduct a morphometric study on coronary ostia and establish their relation with respective aortic sinuses. In addition, branching pattern of the right coronary artery and its dominance were documented. Results: Variations in number and position of ostia in both sinuses were noted. Of the 96 ostia analyzed in the present study, $64.5 \%$ were located below the intercommissural line, $11.4 \%$ above it and $18.7 \%$ at its level. Mean diameter of right and left ostia was measured as $3.03 \mathrm{~mm}$ and $2.9 \mathrm{~mm}$ respectively. Mean distance of right and left ostia from their respective sinuses was found to be $15.14 \mathrm{~mm}$ and $14.20 \mathrm{~mm}$ respectively. Conclusion: Knowledge of normal and variant anatomy of coronary circulation is a vital component in diagnoses of congenital and acquired cardiac diseases. This study will provide additional information about variations of coronary artery to clinicians and manufacturers to plan their approach for safer and successful treatment.
\end{abstract}

Keywords: coronary artery, heart, anatomical variations, sinus of Valsalva, myocardial ischaemia.

\section{Introduction}

Knowledge of normal cardiac anatomy is indispensable for the proper understanding of cardiac disease. In 1761, Morgagni demonstrated the blood supply of cardiac muscle by two coronary arteries. Recent imaging techniques have the potential to accurately visualize the coronary arteries (MURIAGO, SHEPPARD, HO et al., 1997). The Latin term corona or crown appropriately describes coronary arteries that supply the cardiac parenchyma with nutrient blood flow. Two coronary arteries, right and left, arise from anterior and left posterior sinus of the ascending aorta respectively. The right coronary artery (RCA) most commonly arises from an ostium just below the sinotubular junction of the right (right anterior) sinus of Valsalva. Right coronary artery is usually single but as many as four arteries have been observed. The left coronary artery (LCA) arises from the mid position of the left (left posterior) sinus of Valsalva just above the level of the free margin of the aortic valve leaflet and generally below the sinotubular junction (STANDRING, 2005).
Anomalous origin of the coronary arteries is rare but well-described cause of myocardial ischemia and sudden death. The incidence of coronary artery anomalies is approximately $1 \%$ among patients undergoing cardiac catheterization and $0.29 \%$ among autopsy specimens. Most anomalies are incidentally detected and do not create clinical problems (CHEITLIN, CASTRO and MCALLISTER, 1974; ENGEL, TORRES and PAGE, 1975; CHAITMAN, LESPÉRANCE, SALTIEL et al.,1976; KIMBIRIS, ISKANDRIAN, SEGAL et al., 1978; LEVIN, FELLOWS and ABRAMS, 1978). However, 19-33\% of sudden cardiac deaths in the younger population are attributable to coronary artery anomalies (MURIAGO, SHEPPARD, HO et al., 1997; NAVARATNAM, 1993). An anomalous origin of RCA from the left sinus is very rare and its incidence is $0.019 \%$ to $0.49 \%$ in coronary angiography (CHEITLIN, CASTRO and MCALLISTER, 1974; ENGEL, TORRES and PAGE, 1975; CHAITMAN, LESPÉRANCE, SALTIEL et al., 1976; KIMBIRIS, ISKANDRIAN, SEGAL et al., 1978). 
Several studies have been reported on the anatomical positions of coronary ostia because of its significance during coronary catheterization for diagnostic and therapeutic purposes. In most of the investigations, right and left coronary ostia, were observed in the both aortic sinuses (MURIAGO, SHEPPARD, HO et al., 1997, NAVARATNAM, 1993; TURNER and NAVARATNAM, 1996; CAVALCANTI, MELO and VASCONCELOS, 2003). Adequate arterial supply to the heart musculature depends on the good morphological conditions of the right and left coronary arteries. Poor anatomical integrity of the aortic valve and coronary artery malformation could result in reduction of blood flow to the myocardium (ARAI, EPSTEIN, BOVE et al., 1999; CHOO, MCRAE, OLOMON et al., 1999; YACOUB, KILNER, BIRKS et al., 1999). In addition, some factors such as variations in the position of the coronary ostia in relation to the aortic leaflets and the diameter of the ostia may be involved in the possible reduction in coronary blood flow (CAVALCANTI, MELO and VASCONCELOS, 2003).

Therefore, the present study was aimed at investigating the number and position of the coronary ostia, emphasizing their possible clinical implications.

\section{Materials and Methods}

Fifty one cadaveric heart specimens along with the great vessels, fixed in formalin were dissected wherein the pericardium covering the root of the aorta was removed in all specimens. These were collected and numbered irrespective of the age, sex and the cause of death. The ascending aorta was transversely sectioned approximately $1 \mathrm{~cm}$ above the commissures of the aortic leaflets. Subsequently, aorta was opened by a longitudinal incision through its posterior wall between the right and left posterior leaflets. This procedure permitted convenient visualization as well as examination of the morphology of the anterior (A), right posterior (RP) or non coronary and left posterior (LP) aortic leaflets and their respective coronary ostia. Number and position of the orifices were recorded in each specimen.

The distance of coronary ostia $(\mathrm{O})$ from the bottom of the respective aortic sinus (B) and to the commissures $(\mathrm{R}, \mathrm{L})$ of the aortic leaflets were measured using digital caliper $(\mathrm{OB}$, $\mathrm{OR}, \mathrm{OL})$. One extremity of caliper was fixed in the center of the ostium and the other was placed on the bottom of the aortic sinus. Subsequently, movable extremity of the caliper was placed on the nearest commissure to the left $(\mathrm{L})$ and the right $(\mathrm{R})$ of the same ostium (Figure 1 ). The values measured were tabulated and statistically analyzed using Student's t- test.

The position of each orifice was measured in relation to the intercommissural line (RL) and described as being above, below or at the line (Figure 1).

\section{Results}

In the examined specimens, $81.3 \%$ cases were recorded with the origin of RCA and LCA from anterior and left posterior aortic sinus respectively. Apart from this, few variations in terms of origin of the RCA were observed. In one case, this artery arose from the right posterior aortic sinus whereas the LCA from its usual site, the left posterior aortic sinus and no ostium was observed in the anterior aortic sinus (Figure 2a).
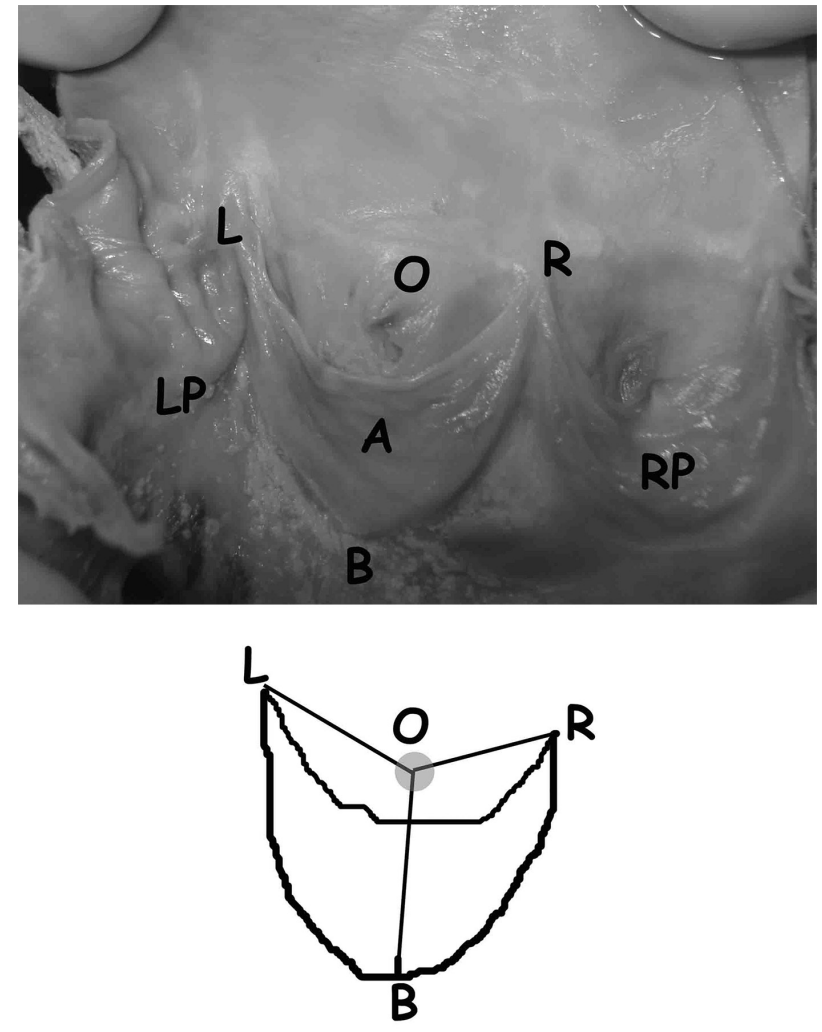

Figure 1. The distance of coronary ostia $(\mathrm{O})$ from the bottom of the respective aortic sinus $(\mathrm{B})$ and to the commissures $(\mathrm{R}, \mathrm{L})$ of the aortic leaflets were measured using digital caliper $(\mathrm{OB}$, $\mathrm{OR}, \mathrm{OL}$ ). One extremity of caliper was fixed in the center of the ostium and the other was placed on the bottom of the aortic sinus. Subsequently, movable extremity of the caliper was placed on the nearest commissure to the left $(\mathrm{L})$ and the right $(\mathrm{R})$ of the same ostium.

In second case, two ostia were observed in the left posterior aortic sinus, the obliquely placed right handed ostium gave rise to RCA and the left handed ostium to LCA. No sign of ostia was observed in anterior and right posterior sinuses (Figure 2b). Third specimen was quite unusual since right posterior sinus showed 2 openings with the LCA arising from the larger opening and the conus artery from the smaller one whereas left posterior aortic sinus did not show any opening (Figure 2c).

Statistical analysis was made on the basis of data obtained from 48 out of 51 specimens excluding aforementioned three highly variant cases.

An accessory orifice was observed in the anterior aortic sinus in 5 specimens which gave origin to the conus artery supplying the outlet component of the right ventricle (Figure $3 \mathrm{a}$ ). Two specimens were presented with 3 ostia in anterior aortic sinus giving rise to the RCA, left anterior descending and circumflex arteries (Figure 3b) while other two specimens with 4 ostia in same sinus with same branches along with conus artery arose in addition (Figure $3 \mathrm{c}$ ).

In the present study, location of ostia was observed below the intercommissural line in $64.5 \%$ cases (Figure $4 a$ ), above this line in $11.4 \%$ cases (Figure $4 \mathrm{~b}$ ) and at the level of line in 

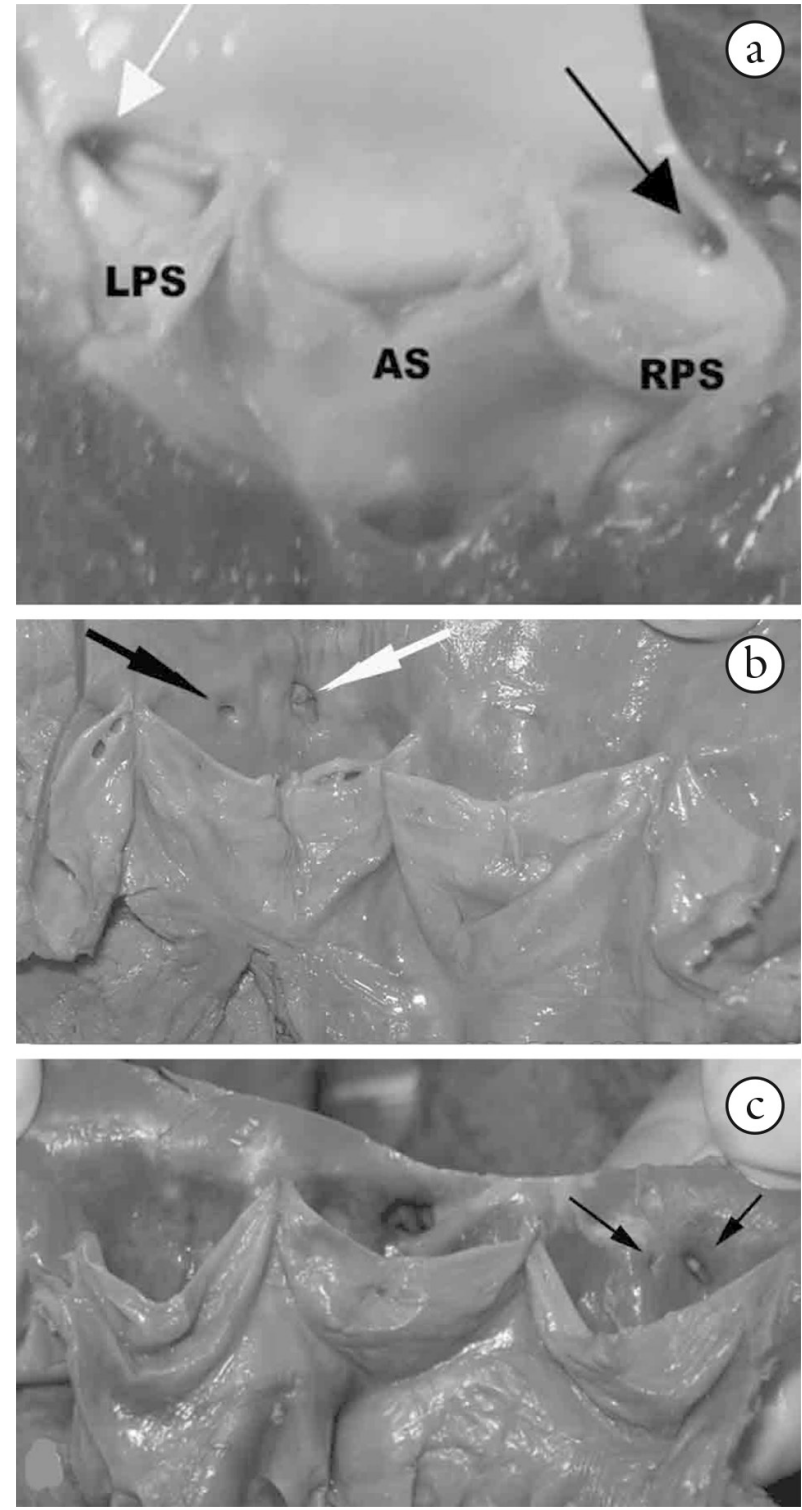

Figure 2. (a) RCA arose from the right posterior (non-coronary) aortic sinus whereas the LCA arose from its usual site, the left posterior aortic sinus and there was no ostium in the anterior aortic sinus. (b) two ostia were observed in the left posterior aortic sinus, the obliquely placed right ostium gave rise to RCA and the one situated on the left gave rise to LCA. The anterior and right posterior aortic sinuses were devoid of ostia. (c) the right posterior (non-coronary) sinus showed 2 openings, with the LCA arising from the larger opening and the conus artery from the smaller one. The left posterior aortic sinus did not show any opening.

Table 1. Showing relation of coronary ostia with sinutubular junction.

\begin{tabular}{cc}
\hline Coronary ostium & Frequency \\
\hline Right and Left below & 62 \\
Right and left at the line & 18 \\
Right and Left above & 11 \\
Right below & 33 \\
Right at the line & 9 \\
Right above & 6 \\
Left below & 29 \\
Left at the line & 9 \\
Left above & 5 \\
\hline
\end{tabular}
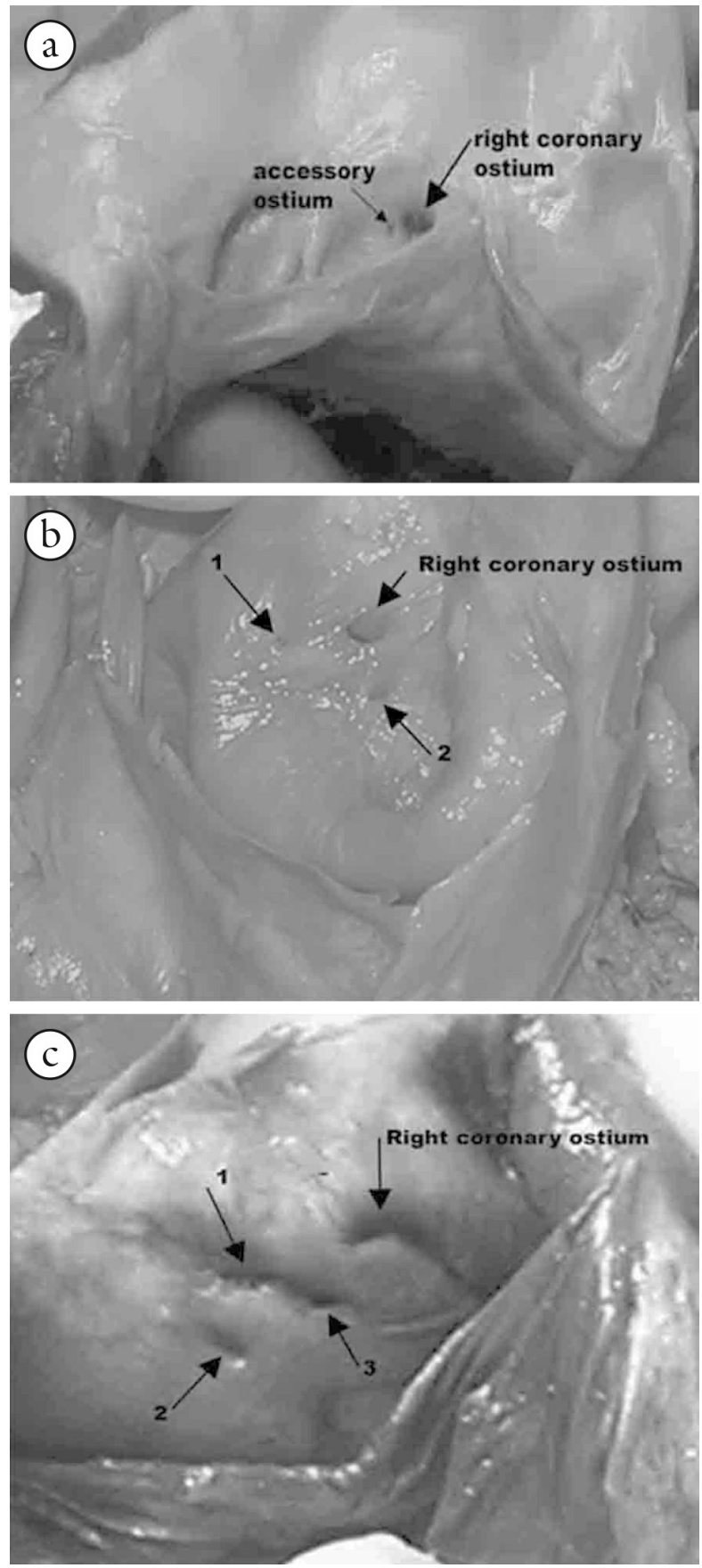

Figure 3. (a) 2 ostia was observed in the anterior aortic sinus. (b) 3 ostia was observed in the anterior aortic sinus. (c) 4 ostia observed in the anterior aortic sinus.

$18.7 \%$ cases (Figure $4 \mathrm{c}$ ). In cases studied, $60.4 \%$ specimens were found with the LCA arising from the left posterior aortic sinus below the intercommissural line, $22.9 \%$ at the line and $10.4 \%$ above it. Source of origin of the RCA from anterior aortic sinus was viewed below the intercommissural line in $68.7 \%$ at the line in $18.7 \%$ and above it in $12.5 \%$ specimens (Table 1). One case with a high take off of the artery $3.2 \mathrm{~cm}$ from the bottom of the sinus was noted.

The mean distances of the left and right orifices from the nearest commissures were tabulated (Table 2) 

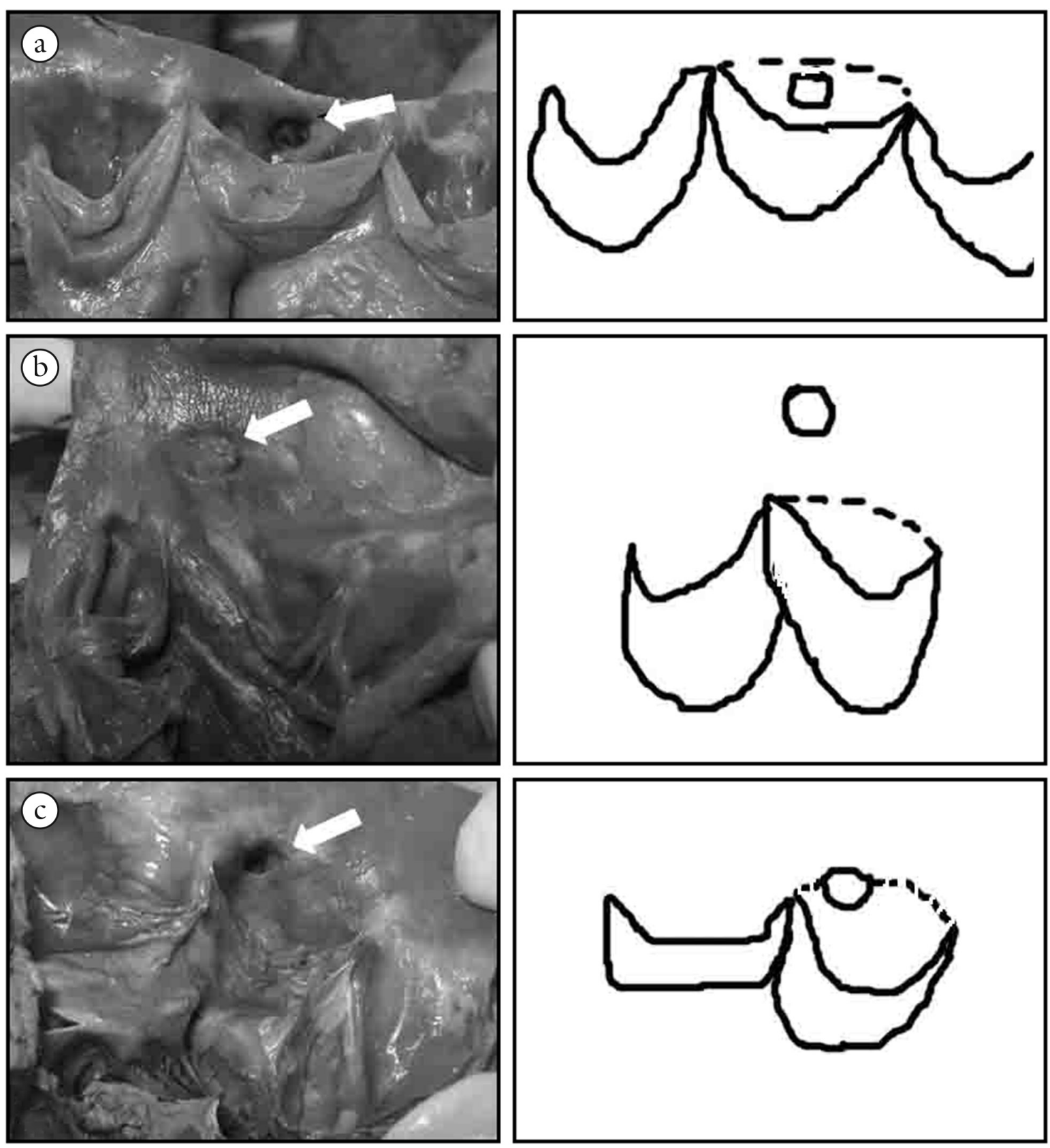

Figure 4. Coronary ostia located below the intercommissural line (a), above it (b) and at its (c).

Table 2. Showing distance of coronary ostia from nearest commissures on right and left sides.

\begin{tabular}{cccc}
\hline Coronary ostium & Commisure & Mean distance $(\mathbf{m m})$ & $\begin{array}{c}\text { Mean intercommissural distance } \\
(\mathbf{m m})\end{array}$ \\
\hline Left & Commisure to the left & $12.8+/-1.7$ & 12.4 \\
& Commissure to the right & $12.1+/-2.3$ & 12.6 \\
\hline \multirow{2}{*}{ Right } & Commissure to the left & $14.7+/-3.3$ & $10.5+/-3.5$ \\
& Commissure to the right & 10.5 & \\
\hline
\end{tabular}

\section{Discussion}

Abnormal origin of the coronary arteries may be a major cause of myocardial ischemia (CHEITLIN, CASTRO and MCALLISTER, 1974; ENGEL, TORRES and PAGE, 1975; CHAITMAN, LESPÉRANCE, SALTIEL et al., 1976;
KIMBIRIS, ISKANDRIAN, SEGAL et al., 1978; LEVIN, FELLOWS and ABRAMS, 1978). Although majority of the coronary artery anomalies are thought to be hemodynamically insignificant, aberrant origin of a coronary artery and its passage between the aorta and the pulmonary trunk has the potential 
to impair myocardial perfusion (ENGEL, TORRES and PAGE, 1975; CHAITMAN, LESPÉRANCE, SALTIEL et al., 1976; KIMBIRIS, ISKANDRIAN, SEGAL et al., 1978).

Abnormal origins of coronary arteries were first observed in $1.6 \%$ of patients' population who underwent cardiac catheterization. Anomalies of arteries were eventually diagnosed with the help of cardiac imaging techniques (JIM, SIU, HO et al., 2005).

A coronary angiographic study conducted by Kaku, Shimizu, Yoshio et al. (1996) on 17731 patients, 56 patients were found with an abnormal origin of the RCA, out of which 44 were with an abnormal origin of the RCA from the left posterior aortic sinus. According to Alexander and Griffith (1956), the incidence of origin of the RCA from the left posterior aortic sinus was estimated to be $0.05 \%$ to $0.1 \%$. Topaz, Demarchena, Perin et al. (1992) carried out a similar study in 13010 patients out of which 80 patients were observed with anomalous coronary arteries. Origin of anomalous RCA was identified in 50 (62\%) patients, of which in 35 arising from the left posterior aortic sinus, in 14 from the right posterior sinus and in 1 from the LCA. Garg, Tewari, Kapoor et al. (2000) observed 39 (0.95\%) out of 4,100 adult patients with anomalous coronary arteries, $19(48.74 \%)$ of them had abnormal origin of the RCA. It was arising from the left posterior aortic sinus in 15 and from the right posterior aortic sinus in 4 patients.

In the current study, two cases were found with the variation associated with the origin of RCA. In the first case, the artery arose from the right posterior aortic sinus whereas the LCA arose from its usual site, the left posterior aortic sinus. There was no ostium in the anterior aortic sinus. Two ostia were observed in the left posterior aortic sinus in the second case, the obliquely placed ostium on the right side gave rise to the RCA and the left one gave rise to the LCA. The anterior and the right posterior aortic sinuses were devoid of ostia.

Benge, Martins and Funk (1980) described cardiac block and posterior wall infarction in a young man with anomalous origin of the RCA from the left posterior aortic sinus. Roberts, Siegel and Zipes (1982) reported similar origin of the RCA in 10 postmortem cases, 3 of whom were sudden death due to exertion.

An anomalous origin of the RCA could lead to angina pectoris, myocardial infarction or sudden death, even in the absence of atherosclerosis, which usually occurs in young athletes during or after exercise (REUL, COOLEY, HALLMAN et al., 2002). A study carried out by Taylor, Rogan and Virmani (1992) on 52 patients with variations in the origin of the RCA reported sudden and asymptomatic death in $25 \%$ of patients. Mortality rate of younger patients (30 or below) was higher than older patients (above 30 years) due to sudden cardiac death $(62 \%$ and $12 \%)$ or death during exercise $(40 \%$ and $2 \%)$ despite low frequency ( $1 \%$ and $40 \%$ respectively) of significant atherosclerotic coronary artery disease.

Microscopic examination of serial sections through 22 human embryos of 5.0-17.5 mm CR length (Carnegie stages XIII-XIX) confirmed that the earliest vessels in the heart wall develop subepicardially near the apex at stage XV. The network extends centripetally and only at stage XVII could coronary arterial stems, communicating with the aortic lumen, be identified. The sequence suggests that confinement of the coronary ostia to the anterior and left posterior aortic sinuses probably occurs because these represent the most accessible contact points for the growing vascular plexus (TURNER and NAVARATNAM., 1996). More than one contact points of vascular plexus with the aortic sinus leads to accessory ostium.

Patel, Gupta, Nath et al. (2007) found similar anomaly in $17 \%$ of the patients on coronary angiography and cardiac MRI. Ishizawa, Tanaka, Zhou et al. (2006) observed in their study, right conus artery to be arising from the right posterior aortic sinus in four specimens. On the contrary, in our study in 5 specimens the conus artery had its origin from the anterior aortic sinus. Rahmatullah, Khan, Nair et al. (1998), Miyoshi, Hara, Shigenmatsu et al. (2005) and El-Menyar, Das, Al-Suwaidi et al. (2006) reported cases wherein three coronary ostia were present in the right posterior aortic sinus, which gave rise to the RCA, left anterior descending and circumflex arteries.

In the present study, 2 of the specimens presented 3 ostia in the anterior aortic sinus which gave rise to the RCA, left anterior descending and circumflex arteries. On the other hand, 4 ostia were observed in 2 other specimens wherein the conus artery arose additionally from the fourth ostium.

Motamedi, Hemmat, Kalani et al. (2009) observed that the RCA originated from the ascending aorta $5 \mathrm{~cm}$ above the sinotubular junction superior to the right posterior aortic sinus. Rotgé, Ferrando, Sahagún et al. (1999); Alpaslan and Onrat (2002) also reported the anomalous origin of the RCA from the tubular portion of the ascending aorta (). High origin of the ostium of the RCA outside the aortic sinuses is extremely rare. We came across one case showing a high take off of the artery $3.2 \mathrm{~cm}$ from the bottom of the sinus. Turner and Navaratnam (1996) reported that from the functional point of view it would be beneficial that both coronary ostia were above the intercommissural line. This would make the coronary blood flow easier during ventricular systole and would also prevent the obstruction of the ostia when the aortic valve was opened. However Cavalcanti, Melo and Vasconcelos (2003) differs as it is well known in cardiac physiology that blood flows to the coronary arteries mainly during the diastolic phase of the cardiac cycle.

In the present findings $11.4 \%$ cases were consistent with the findings of Muriago, Sheppard, Ho et al. (1997) who found only $13 \%$ of the ostia above the intercommissural line but there was a notable difference with the findings of Turner and Navaratnam (1996) and Navaratnam (1993) who found $16 \%$ of the ostia above the.

In view of the left coronary ostium, our results (above intercommissural line in $10.4 \%$ and at this line in $22.9 \%$ cases) were similar to Cavalcanti, Melo and Vasconcelos (2003) but differ from the results of Muriago, Sheppard, Ho et al. (1997) who reported a left coronary ostium above the line in $22 \%$ and at the level of the intercommissural line in $9 \%$. With regard to the right coronary ostium, same authors reported that the right coronary ostium was below the intercommissural line in $78 \%$ of their case series. Muriago, Sheppard, Ho et al. (1997) and Cavalcanti, Melo and Vasconcelos (2003) showed that the coronary ostia are not located in the center of each aortic sinus but they are displaced to the commissure located to the right of the ostia. Similar findings were noticed with respect to the location of the right coronary ostium in present study wherein 
the RCA arose below the intercommissural line in $68.7 \%$, at the level of line in $18.7 \%$, and above in $12.5 \%$ specimens.

As far as distance from neighbouring commissures are concerned, it is worth noting that in present study the left coronary ostium was located almost in the central region of the related aortic sinus, which is in concordance with the studies reported by Navaratnam (1993); Turner and Navaratnam (1996); Cavalcanti, Melo and Vasconcelos (2003).

McAlpine (1975) proposed that the location of the right coronary ostium in the right half of the corresponding aortic sinus is appropriate, because the right coronary artery is destined to pass around the tricuspid valve. As a result it will be having a more direct course than if it originated in the left or medial portion of the sinus. According to the author, displacement of the left coronary ostium to the right would be more appropriate because the anterior and left parts of the heart are supplied by the left coronary artery. Muriago, Sheppard, Ho et al. (1997) stated that the more central location of the left coronary ostium is justified, because, after its origin, the left coronary artery heads to the space between the pulmonary trunk and the left auricle, branching right after that.

We observed no significant differences in the deviation with respect to diameter of the left and right coronary ostium. The knowledge of these data is imperative for clinical and surgical practice as alterations in coronary flow may be caused by modifications in the diameter, position, and anatomic relations of the coronary ostia.

It is well established that an anomalous origin of the right coronary artery can lead to angina pectoris, myocardial infarction, or sudden death, in the absence of atherosclerosis. The pathophysiologic basis for this association, however, is unclear. Mechanical compression of the right coronary artery by the great vessels is the usual explanation, because the anomalous right coronary artery generally courses between the aorta and the pulmonary artery to its normal position. The oblique angle at the juncture of the anomalous right coronary artery and the left coronary sinus produces a slit-like orifice in the aortic wall that can collapse during exercise (HO and STRICKMAN, 2002). Recently, Kaku, Shimizu, Yoshio et al. (1996) suggested that the proximal portion of the right coronary artery, situated between the aorta and the pulmonary artery, might be more prone to spasm than it would be otherwise.

Diagnosis of coronary anomalies is important in patients undergoing coronary arteriography, coronary interventions and cardiac surgery. Variations in the frequency of primary congenital coronary anomalies may possibly have a genetic background.

\section{References}

ALEXANDER, RW. and GRIFFITH, GC. Anomalies of the coronary arteries and their clinical significance. Circulation, 1956, November., vol. 14, n. 5, p. 800-805. http://dx.doi.org/10.1161/01.CIR.14.5.800. PMid:13374855.

ALPASLAN, M. and ONRAT, E. Anomalous origin of right coronary artery above the sinus of Valsalva: observation by transthoracic echocardiography. Journal of the American Society of Echocardiography, 2002, March, vol. 15, n. 3, p. 264-266. http://dx.doi.org/10.1067/ mje.2002.117900. PMid:11875391.
ARAI, AE., EPSTEIN, FH., BOVE, KE. and WOLFF, SD. Visualization of aortic valve leaflets using black blood MRI. Journal of Magnetic Resonance Imaging, 1999, November, vol. 10, n. 5, p. 771-777. http://dx.doi.org/10.1002/(SICI)1522-2586(199911)10:5<771::AIDJMRI22>3.0.CO;2-Q. PMid:10548787.

BENGE, W., MARTINS, JB. and FUNK, DC. Morbidity associated with anomalous origin of the right coronary artery from the left sinus of Valsalva. American Heart Journal, 1980, January, vol. 99, n. 1, p. 96-100. http://dx.doi.org/10.1016/0002-8703(80)90319-1. PMid:7350757.

CAVALCANTI, JS., MELO, NC. and VASCONCELOS, RS. Morphometric and topographic study of coronary ostia. Arquivos Brasileiros de Cardiologia, 2003, October, vol. 81, n. 4, p. 359-362, 355-358. http://dx.doi.org/10.1590/S0066-782X2003001200003. PMid:14666278.

CHAITMAN, BR., LESPÉRANCE, J., SALTIEL, J. and BOURASSA, MG. Clinical, angiographic, and hemodynamic findings in patients with anomalous origin of the coronary arteries. Circulation, 1976, January, vol. 53, n. 1, p. 122-131. http://dx.doi.org/10.1161/01. CIR.53.1.122. PMid:1244233.

CHEITLIN, MD., CASTRO, CM. and MCALLISTER, HA. Sudden death as a complication of anomalous left coronary origin from the anterior sinus of Valsalva, a not-so-minor congenital anomaly. Circulation, 1974, October, vol. 50, n. 4, p. 780-787. http://dx.doi. org/10.1161/01.CIR.50.4.780. PMid:4419670.

CHOO, SJ., MCRAE, G., OLOMON, JP., ST GEORGE, G., DAVIS, W., BURLESON-BOWLES, CL., PANG, D., LUO, HH., VAVRA, D., CHEUNG, DT., OURY, JH. and DURAN, CM. Aortic root geometry: pattern of differences between leaflets and sinuses of Valsalva. The Journal of Heart Valve Disease, 1999, July, vol. 8, n. 4, p. 407-415. PMid:10461241.

EL-MENYAR, AA., DAS, KM. and AL-SUWAIDI, J. Anomalous origin of the three coronary arteries from the right aortic sinus Valsalva: role of MDCT coronary angiography. The International Journal of Cardiovascular Imaging, 2006, October, vol. 22, n. 5, p. 723-729. http://dx.doi.org/10.1007/s10554-005-9062-7. PMid:16642404.

ENGEL, HJ., TORRES, C. and PAGE, HL Jr. Major variations in anatomical origin of the coronary arteries: angiographic observations in 4,250 patients without associated congenital heart disease. Catheterization and Cardiovascular Diagnosis, 1975., vol. 1, n. 2, p. 157-169. http://dx.doi.org/10.1002/ccd.1810010205. PMid:1222415.

GARG, N., TEWARI, S., KAPOOR, A., GUPTA, DK. and SINHA, N. Primary congenital anomalies of the coronary arteries: Arteriographic study. International Journal of Cardiology, 2000., vol. 74, , n. 1, p. 39-46. http://dx.doi.org/10.1016/S0167-5273(00)00243-6. PMid:10854679.

HO, JS. and STRICKMAN, NE. Anomalous origin of the right coronary artery from the left coronary sinus: case report and literature review. Texas Heart Institute Journal, 2002, vol. 29, n. 1, p. 37 39. PMid:11995848.

ISHIZAWA, A., TANAKA, O., ZHOU, M. and ABE, H. Observation of root variations in human coronary arteries. Anatomical Science International, 2006, March, vol. 81, n. 1, p. 50-56. http://dx.doi. org/10.1111/j.1447-073X.2006.00130.x. PMid:16526597.

JIM, MH., SIU, CW., HO, HH., MIU, R., LAM, YM., LAM, L., CHAN, RH. and LEE, SW. Anomalous origin of the right coronary artery from the left coronary sinus: incidence, characteristics and a systematic approach for rapid diagnosis. Journal of Interventional Cardiology, 2005, vol. 18, p. 101-106.

KAKU, B., SHIMIZU, M., YOSHIO, H., INO, H., MIZUNO, S., KANAYA, H., ISHISE, S. and MABUCHI, H. Clinical features of prognosis of Japanese patients with anomalous origin of the coronary 
artery. Japanese Circulation Journal, 1996, October, vol. 60, n. 10, p. 731-741. http://dx.doi.org/10.1253/jcj.60.731. PMid:8933235.

KIMBIRIS, D., ISKANDRIAN, AS., SEGAL, BL. and BEMIS, CE. Anomalous aortic origin of coronary arteries. Circulation, 1978, October, vol. 58, n. 4, p. 606-615. http://dx.doi.org/10.1161/01. CIR.58.4.606. PMid:567544.

LEVIN, DC., FELLOWS, KE. and ABRAMS, HL. Hemodynamically significant primary anomalies of the coronary arteries. Angiographic aspects. Circulation, 1978, July, vol. 58, n. 1, p. 25-34. http:// dx.doi.org/10.1161/01.CIR.58.1.25. PMid:348342.

MCALPINE, WA. Heart and coronary arteries: anatomical atlas for clinical diagnosis, radiological investigation, and surgical treatment. Berlin: Springer-Verlag, 1975, p. 134.

MIYOSHI, S., HARA, Y., SHIGENMATSU, Y., OHTSUKA, T., OGIMOTO, A., OHKURA, T. and HIGAKI, J. Separate origins of three coronary arteries arising from the right sinus of Valsalva. The Canadian Journal of Cardiology, 2005, April, vol. 21, n. 5, p. 451-452. PMid:15861264.

MOTAMEDI, MH., HEMMAT, A., KALANi, P., REZAEE, MR. and SAFARNEZHAD, S. High take-off of right coronary artery: an extremely rare case of RCA anomaly. Journal of Cardiac Surgery, 2009, May-June, vol. 24, n. 3, p. 343-345. http://dx.doi. org/10.1111/j.1540-8191.2009.00834.x. PMid:19438794.

MURIAGO, M., SHEPPARD, MN., HO, SY. and ANDERSON, $\mathrm{RH}$. Location of the coronary arterial orifices in the normal heart. Clinical Anatomy, 1997., vol. 10, n. 5, p. 297-302. http:// dx.doi.org/10.1002/(SICI)1098-2353(1997)10:5<297::AID$\mathrm{CAl}>3.0 . C O ; 2-\mathrm{O}$. PMid:9283725.

NAVARATNAM, V. Design of heart valves: a review. Clinical Anatomy, 1993., vol. 6, n. 6, p. 327-332. http://dx.doi.org/10.1002/ ca. 980060602 .

PATEL, KB., GUPTA, H., NATH, H., AQEL, RA., ZOGHBI, GJ., SOTO, B., PERRY, GJ. and LLOYD, SG. Origin of all three major coronary arteries from the right sinus of Valsalva: clinical, angiographic, and magnetic resonance imaging findings and incidence in a select referral population. Catheterization and Cardiovascular Interventions, 2007, April 1., vol. 69, n. 5, p. 711-718. http:// dx.doi.org/10.1002/ccd.21078. PMid:17330267.

RAHMATULLAH, SI., KHAN, IA., NAIR, VM., KANNAN, T., VASAVADA, BC. and SACCHI, TJ. Separate origins of all three major coronary arteries from the right sinus of Valsalva: a rare coronary artery anomaly. Cardiology, 1998, July, vol. 90, n. 1, p. 72-74. http:// dx.doi.org/10.1159/000006821. PMid:9693176.

REUl, RM., COOLEY, DA., HALLMAN, GL. and REUL, GJ. Surgical treatment of coronary artery anomalies: report of a 37 1/2year experience at the Texas Heart Institute. Texas Heart Institute Journal, 2002, vol. 29, n. 4, p. 299-307. PMid:12484614.

ROBERTS, WC., SIEGEL, RJ. and ZIPES, DP. Origin of the right coronary artery from the left sinus of valsalva and its functional consequences: analysis of 10 necropsy patients. The American Journal of Cardiology, 1982, March, vol. 49, n. 4, p. 863-868. http://dx.doi. org/10.1016/0002-9149(82)91970-1. PMid:7064835.

ROTGÉ, PP., FERRANDO, NA., SAHAGÚN, NB., HERRERO, SM. and CAPMANY, RP. Arteria coronaria derecha con origen, trayecto anómalo e isquemia miocárdica. Revista Espanola de Cardiologia, 1999, December, vol. 52, n. 12, p. 1154-1156. PMid:10659663.

STANDRING, S. (Ed.). Gray's anatomy. the anatomical basis of clinical practice. New York. Elsevier Churchill Livingstone, 2005. p. 1014-1017.

TAYLOR, AJ., ROGAN, KM. and VIRMANI, R. Sudden cardiac death associated with isolated congenital coronary artery anomalies. Journal of the American College of Cardiology, 1992, September, vol. 20 , n. 3, p. 640-647. http://dx.doi.org/10.1016/07351097(92)90019-J. PMid:1512344.

TOPAZ, O., DEMARCHENA, EJ., PERIN, E., SOMMER, LS., MALLON, SM. and CHAHINE, RA. Anomalous coronary arteries: angiographic findings in 80 patients. International Journal of Cardiology, 1992, February, vol. 34, n. 2, p. 129-138. http://dx.doi. org/10.1016/0167-5273(92)90148-V. PMid:1737663.

TURNER, K. and NAVARATNAM, V. The positions of coronary arterial ostia. Clinical Anatomy, 1996, vol. 9, n. 6, p. 376-380. http://dx.doi.org/10.1002/(SICI)1098-2353(1996)9:6<376::AIDCA3>3.0.CO;2-9. PMid:8915616.

YACOUB, MH., KILNER, PJ., BIRKS, EJ. and MISFELD, M. The aortic outflow and root: a tale of dynamism and crosstalk. The Annals of Thoracic Surgery, 1999, September, vol. 68, no. 3, sup. Suppl, p. S37-S43. http://dx.doi.org/10.1016/S0003-4975(99)00745-6. PMid:10505990.
Received August 15, 2014

Accepted July 8, 2015 